\title{
The Self and the Institution
}

\author{
The Transformation of a Narrative Genre
}

\author{
Birgit Hertzberg Kaare
}

\begin{abstract}
Media researchers have not been much preoccupied with a genre named Digital Storytelling. Since its origin in the early 90 s, it has spread from California to the rest of the United States and has been evolving for several years now as a media practice around the globe. I therefore want to draw more attention to digital storytelling, here understood as a specific genre developed at the Center for Digital Storytelling (CDS) in California and defined as a short, first-person video narrative that combines voice recordings, still and moving images, and music or other sounds (www.storycenter.org). Such storytelling is regarded as both a movement and a method; and it is in its idea a short personal story, about the self. In the subtitle of his book Digital Storytelling, the leader of the center, Joe Lambert, highlights that this type of narratives are Creating Community through Capturing Lives of individuals (Lambert 2009). This genre is embedded in a democratic and empowering ideology. Along these lines, the main concern of this article is to discuss whether a change can be observed in the digital storytelling genre from an individualistic perspective to a more collective perspective - a shift from narrating selves to narrating communities. In examining this question, this work draws upon 45 films produced by bachelor students at the University of Oslo in 2010 and 2011.
\end{abstract}

Keywords: digital storytelling, narratives, individual and collective, identity

\section{Introduction}

Digital storytelling is a specific form of producing digital personal narratives for either a restricted or narrowly defined audience or distribution via the Internet (Meadows 2003: 189). The basic form of digital stories is a 2-4 minute film consisting of the author's images (and video) coordinated with her/his own voiceover to tell a story. The story takes the form of a first-person narrative enhanced with a soundtrack, image pan (movement across the horizon) and zoom effects. This specific genre, here referred to as the classical digital story or the CDS model of digital storytelling, was developed in the mid-1990s and has been evolving for several years as a media practice around the globe (Hartley and McWilliam 2009, Lambert 2009b, Lundby 2008, Meadows 2003). Most productions within this genre of digital stories follow the format outlined at the Center for Digital Storytelling (CDS) in California. In their presentation on the Internet, the CDS defines a digital storyteller as "anyone who has a desire to document life experience, ideas, or feelings through the use of story and digital media for digital storytelling" (www.storycentre.org). The focus is clearly on the individual and the narrating self; 
digital storytelling is regarded as both a method and a movement to give people a voice through the use of computer tools.

According to Joe Lambert, the leader of the CDS, there is a clear connection between digital storytelling, popular culture and the storytelling of everyday life: "We approach the storytelling part of our work as an extension of the kind of everyday storytelling that occurs around the dinner table, the bar, or the campfire" (Lambert 2009: 14). Digital storytelling is a multimodal version of the universal praxis of turning experiences and events into narratives. Multimodal narratives combine elements from oral, visual and written storytelling in one and the same product (Kaare and Lundby 2008b). Even though the CDS has helped thousands of people tell their digital stories, the films are seldom published on the Internet and are more often kept as private products by the producers.

Digital storytelling might be characterised as a Western media practice that has been adopted world wide (Lundby 2009: 176-178). In recent years several digital storytelling projects have inspired more community engagement (Burgess and Klaebe 2009, Tacchi 2009, Carpentier 2009). Applications of Digital Storytelling can be found in youth programs (Hull 2003, Hull and Nelson 2005, Hull and Katz 2006, Lambert 2009a: 95), schools (Lowenthal 2009), health and human services and cultural institutions (Lambert 2009a: 91-105, McWilliam 2009), to name but a few examples.

Digital storytelling has always been an institutionalised practice. Recent developments, however, have shown a greater focus on the institutions themselves than in the genre's early days, in not only the production but even the content of digital stories. The question thus arises whether this growing interest in digital stories from the perspective of the institution rather than the individual narrator might lead to modifications of the original characteristics of the genre. Accordingly, the following question will be discussed in this article:

How does the digital storytelling genre of the CDS model change when the narrative focus is on an institution instead of the storyteller?

The line of reasoning presented here is based on an international research project called "Mediatized Stories: Mediation Perspectives on Digital Storytelling among Youth" (www.intermedia.uio.no/mediatized/). The starting point for this project was the telling of digital stories of the CDS model. Throughout 2010 and 2011, I have been running a bachelor course at the University of Oslo (MEVIT 3810) in which students have produced both digital stories about their own lives and experiences, and digital stories that are used for the celebration of the University's bicentennial (http://www.muv.uio. no/digitale-fortellinger/index.xml). Their work with these films and their reflections on the genre's potentials and shortcomings (presented in five reports) have been used as valuable sources for evaluating the genre's possibilities and limitations when it is used for institutional purposes.

\section{The Production of a Narrative Genre}

Digital stories are short films consisting of the author's images (and video) coordinated with their own voiceover to tell a story. Such storytelling is in its idea a personal narrative about the self. The paradigmatic principles of digital storytelling, as developed by the Center for Digital Storytelling (www.storycenter.org/principles.html), are in short: 1 . Everyone has many powerful stories to tell; 2. Listening is hard; 3. People see, 
hear, and perceive the world in different ways; 4. Creative activity is human activity; 5. Technology is a powerful instrument of creativity; and 6. Sharing stories can lead to positive change.

From these principles follows a core methodology that is introduced to the storytellers in a workshop. As the most important element of the story, the narrative defines and leads all aspects of the process, and it is developed as a written text. The narratives are then told with a personal voice, as "me" or rather "I" stories (Mead 1934). Pre-existing visual archives, e.g. family albums and home videos, are sources of inspirations for these stories. In order to learn about the narrative process and story design, the facilitators give a lecture entitled "The Seven Steps of Digital Storytelling". This lecture focuses on "Owning Your Insights; Owning Your Emotions; Finding the Moment; Seeing Your Story; Hearing Your Story; Assembling Your Story; [and] Sharing Your Story" (Lambert 2009a: 29-47). To discuss their ideas the storytellers are taken into a group script review process called "the Story Circle". This process is regarded as just as important as the finished products - the films. This process might be therapeutic. The films are shared in a final presentation to the group. Standard software (Adobe Photoshop and Adobe Premiere in former years) are used for the actual production.

Are digital stories of the CDS model a specific media genre? They might be categorized thus with respect to both content and production process. Digital storytelling shares similarities with other media genres, especially the micro-documentary and video blog. A genre can be said to exist when we have a group of texts that share some resemblances of content and/or form. In genre theory it is relevant to look at both the sender and receiver of the text, as genre is a part of a social process (Lindstad 2006). The Story Circle's production process is specific to digital storytelling. The implementation of the Seven Steps in the creation of the narrative, "coupled with the short duration, [is] what differentiate[s] a CDS digital story from other types of digital stories or other media" (Lowenthal 2009: 253). In digital storytelling, the senders and the primary receivers are all participants in the Story Circle, which is one reason to label digital stories in the CDS model a specific genre (Lindstad 2006).

\section{The Diffusion of Digital Storytelling}

Kelly McWilliam has done a survey in which she located more than 300 digital storytelling programs operating around the world with a prominent online presence (2009: 37-75). Examples of digital storytelling projects produced under the CDS model, and usually run by staff from the CDS, are numerous. Since its origin in the early 90 s, digital storytelling has been developed and used in a wide range of contexts. It has spread from California to the rest of the United States, and from there to other places all over the globe. One interesting example is the project Capture Wales, led by Daniel Meadows in cooperation with BBC Wales. The stories produced in this project were essentially personal stories and were explicitly intended for publication on the Internet. This project resulted in an original and sustainable contribution to community self-expression in Wales (Meadows 2003, Meadows \& Kidd 2009, Thumim 2006). Meadows points out that digital stories are unlike any previous forms of broadcast material: they are, essentially, films, but they are not "movies" since they are mostly made up of still pictures. They are somewhat more akin to radio-with-pictures, but with production values that come 
from the scrapbook rather than the studio - and they certainly do not look like ordinary television programs (Meadows 2003). These digital stories can be seen on the Capture Wales website (http://www.bbc.co.uk/capturewales/).

As the American researcher Glynda Hull writes, "digital storytelling is an internally diverse and necessarily dynamic and evolving genre" (2005 :233). Over the years the practice of digital storytelling has evolved to fit numerous different contexts (Hartley \& McWilliam 2009, Lundby 2008, McWilliam 2009), but despite this, digital storytelling has remained surprisingly stable as a genre, at least when it comes to its outer form and the production process. This is probably due to the fact that digital storytelling is mostly used by various institutions that provide training in storytelling according to the rigid paradigmatic principles that were developed in California. Today the genre might be characterised as balancing on the edge between the original individual "I"-focused narrative, or the autobiographical narrative, and the micro-documentary, in some cases approaching the informational film. This turn has to some extent impacted the identity aspects of digital storytelling.

\section{Individual and Collective Identity in Digital Storytelling}

According to Lambert, "the idea of digital storytelling has resonated with many people because it speaks to an undeniable need to constantly explain our identities to each other. As we improvise our ways through our multiple identities, any tool that extends our ability to communicate information about ourselves to others becomes invaluable" (2009: 14-15). To CDS it is a must that the stories told are stories from our lives. They ought to be autobiographical. They can be either about experiences, events or reflections. Lambert characterises the content of the stories according to a few common themes centring on the narrating self: The Story About Someone Important, The Story About an Event in My Life, The Story About a Place in My Life, The Story About What I Do, and Other Personal Stories (Lambert 2009a: 24-27). The creators of the digital stories genre express a belief in the transformative power of narrative: "We need to listen deeply to each other's stories, the moments of life experience and change that form the resonant values that define who we are" (Lambert 2006: xxi). It is little wonder that the theoretical starting point for exploring digital storytelling has mainly been literature on identity, as identity is perceived as the link between narrative and the construction of a sense of self (Hull 2003, 2007).

The genre of digital storytelling as an institution (Lundby 2009: 181), with its economy of expression, strong dramaturgical demands and expectations for the motivations of the storyteller to benefit the collective, guide the individual to construct a narrative which demonstrates an emotional attachment to something beyond the self. The seemingly simple paradigmatic principles of the genre lead the individual storyteller to construct her/ his narratives for the benefit of the community. The story should be shared and contain shared values (Kaare 2008). The storyteller is expected to use certain narrative techniques that lead the individual to connect itself to the community and the larger society. "Beyond individual expression" is how the Australian researchers Jerry Watkins and Angelina Russo describe their work with digital storytelling in cultural institutions (2009: 269).

Two main characteristics shared by various forms of digital self-representational narratives are their assumed authentic forms of expressions and the expectations that the content of the stories should be based upon the autobiographies of the narrators. Digital 
stories of the CDS model therefore represent the performance of mediated identities perceived as "authentic" (Kaare and Lundby 2008a, Guignon 2004, Tolson 2001). The digital storytelling genre favours a focus on the individual, as these stories are meant to be self-representational. The production of various types of digital self-representational narratives might be seen as creative responses both to individual life experiences and to traditions of narration. From this perspective they might be characterised as narrative constructions with implications on both a personal and a socio-cultural level. By participating in the Story Circle and negotiating how their stories should be constructed and interpreted, the narrators are connected to the collective identity of the storytelling group as well as to the community that organises the storytelling (Kaare 2008, Lambert $2009 b$ ). In some projects, the narrators' interest in the project is prompted by their desire to be recognised as members of a community (Hull and Katz 2006: 45). The digital stories might become pathways for the reflexive "I" to connect its life and narratives to a community and collective values.

\section{Implementing the CDS model at the University}

The University of Oslo celebrated its bicentennial in 2011. Over the course of 2010 and 2011 I was running a bachelor course in which students practise digital storytelling and made films for this event. The films have been unveiled on the University's websites, along with a recognition of the most outstanding films (http://www.muv.uio.no/digitalefortellinger/index.xml).

At the beginning of the course students were guided to produce films according to the strict CDS model. They produced stories that focused on their individual life stories. Their training was carried out in a three-day workshop with Joe Lambert. A number of moving and very personal stories were made and shown in closed arrangements mainly for students from the groups. After being introduced to the history of the University, the students were directed to make short films for the bicentennial celebration. The students were instructed to make their films according to the guidelines they had been taught in the production of their personal digital stories; the films about the University should be told as first-person stories following the pattern of the CDS model. The students were given various works from the digital stories literature to acquire insight into the main production principles of the genre. Altogether, 45 films were produced.

Each student had to produce both her/his own individual film for the bicentennial as well as make a film in a group of two or three students. Each group wrote a report in which the students evaluated the use of digital storytelling as a genre based on their experience in producing these films. The films were made on commission from MUV, the Museum for the History of Science at the University of Oslo (http://www.muv. uio.no/). The MUV has been responsible for the historical content and facts presented in the films, and has the right to use these films for their purposes. The museum staff assisted students with the difficult work of finding suitable themes, photos and other visual materials, and they were establishing contacts between the students and various resource persons. They also gave their final approval of the storyboards before the films were set to production. This course gave the students competence in making a kind of digital stories that are being used more and more by museums and various other cultural institutions, even private business concerns. 


\section{Modifying the Principles of Digital Storytelling}

During the two courses, the students produced 19 individual films with personal content based on their own experiences and stories. For the University's bicentennial, they produced 19 individual films and 7 group films. From the beginning, the intention was to stick as close as possible to the digital stories genre while making films for public use. The production process behind digital stories is unlike most other media genres in being based on very strict procedures, since digital storytelling is presented not only as a genre but also a method. It therefore makes sense to compare the 45 films to the main criteria for digital storytelling in order to see to what extent the mission to produce films for the University changed the genre.

The CDS model's main characteristics had to be modified in several of the films. While almost all the 19 films based on the student's own lives and experiences were created without too many problems fulfilling the characteristics of digital storytelling, it turned out that in the films produced for the University even the demand for a first-person narrative was in some cases a bit difficult to fulfil. When referring to historical documents like letters, we experienced that using the voices of other persons to read those loud was a good solution while referring to the past. While the films remained first-person narratives, sometimes other voices than the voice of the narrator had to be introduced.

A classical digital story usually has a very short time limit; films longer than three minutes are not very common. The films with personal content were usually easy to keep within these time limits, while several of the films for the University, especially those made by groups, had a tendency to contain a certain amount of necessary information which could extend the film beyond the prescribed 2-4 minutes.

In principle, digital stories are based on a good narrative, after which pictures may be found or produced to illustrate the narrative. However, several of the films produced for the University arose from interesting historical photos or documents, for which the students had to invent some plot or idea to write a good narrative. A classical digital story should be based on private photos, preferably from the family album. This was of course not the case for the 26 historically oriented films, since the starting point for the stories often was the rich photo archives from the MUV. However, several of the best films about the University contained a mixture of archive photos and private photos provided by the students.

To the CDS the production process is regarded as important as the film itself, which was also the case when the students produced their first films based on their personal experiences. They took part in a Story Circle and discussed their ideas with each other and the facilitators, thus taking part of a group process they all seemed to appreciate. This process was finished by sharing the films with the group in a private setting. In contrast to the process-oriented focus of this first production, the production of the films for the University was above all focused on the quality of the films. These films were to be presented in public, published on the bicentennial's websites, submitted to competitions and (not least) given marks for passing the course. In a process intended to simulate the Story Circle, suitable themes for University films were presented and discussed, but this did not really function as a Story Circle. Making University films in groups, however, to a certain extent served as a group script process.

The CDS introduced the Seven Steps as the most important principles for creating digital stories. Our experience soon showed that the most effective approach to the three 
different types of film production was to apply the Seven Steps as a guide to constructing a good narrative. They turned out to be very difficult to fulfil, but were nevertheless of utmost importance in keeping the University films within the genre criteria. The most challenging task for the production of the University films was applying a personal perspective to historical material. It turned out that among the Seven Steps of Storytelling, the second step, "Owning Your Emotions", was most difficult to fulfil since the young narrators had little emotional investment in the University's history to draw upon beforehand. On the other hand, if the students did not succeed in giving their films about the University a personal, emotional content, they were at risk of producing an informational film rather than a digital story.

\section{Discussion}

There are of course differences between producing traditional personal digital stories and making either individual or group-based stories on commission from the University. The students' experiences and reflections based on the making of personal versus bicentennial films are many - and so are mine as the leader of the course. What happened when the students were asked to construct and produce digital stories that followed the CDS model, yet were not their own personal stories? What happened when they were instructed to practise digital storytelling using sources that had little connection to their personal lives?

Several tensions occurred when the students tried to apply what they had learned about the CDS model to the production of the bicentennial films. The method implicates that the digital storytellers are "ordinary people" (Thumim 2006), which means amateurs. But these were students of Media and Communication; they were not only highly media literate, but more or less professional culture workers. No wonder some of them to some extent were in opposition both to the method and the facilitators; some strongly advocated using their knowledge of more advanced technological solutions than was allowed. Some experienced a challenge to their professional pride when they had to produce such technologically modest products as digital stories.

To take the perspective of the institution and tell a story from the University's point of view was no easy task. Some of the students wanted to promote their individual and subjective ways of narrating the digital story without any deep knowledge of the film's historical theme, and therefore came into several disputes with the Museum staff. Their artistic ambitions also in some cases clashed with the MUV staff's concentration on historical facts. Some narrators maintained a strong sense of ownership over their stories and resisted any necessary corrections to the films before their publication for the jubilee.

The films made as group productions offered some interesting perspectives on individual versus group production within a genre so heavily based on the personal and individual touch. Who should be the narrator - and on behalf of whom? The whole group? Some problems arose in adjusting to both other members of the group and the genre's claim of taking the individual's perspective as its starting point. The premises behind the production of the group-based films turned out to involve the most substantial departure from the traditional CDS model. The group activities of both writing the narratives and reading the stories might be seen as a huge departure from the personal, individual focus that is the hallmark of the genre. On the other hand, even in the production of traditional, individual digital stories, the filmmakers are expected to cooperate 
with the rest of the participants in the workshop and the Story Circle in order to exchange ideas, adjust their stories according to the others' responses and to a certain degree work through the Seven Steps together. As Lambert writes, "In our workshops, we approach this journey as a facilitated group process" (Lambert 2009a: 47).

While the documentary strives towards objectivity, digital storytelling rather focuses on the subjective. This is the most important difference between these two genres. The digital stories produced for the University share some kinship with documentaries, but might better be categorised as personal-historical narratives in which the strength of the stories is still the personal touch. What is mediated is not the experience of the narrating self, but reflections about the history of scolarship and the University, and in some films, the experiences of someone else connected to the University's history. This is done by connecting the University's history to the narrator's own situation as a student today, or by telling about the life experiences of others in which the historical information is a necessary and inevitable part of the narrative.

Compared to the digital representations of identity and self on various social websites (Lundby 2008), digital storytelling as a method and a movement has a strong intention to initiate narratives that connect the individual to the surrounding community (Lambert 2009b: 87-89). The genre therefore has the potential of making the individual use her/ his digital narrative to attach to places, through e.g. story mapping or to institutions (Lambert 2009: 91), thereby narrating the self into the community.

As a digital tool, classical digital storytelling might appear rather limited to young digital natives of media-saturated societies, who are used to far more advanced programs and technically more ambitious projects. While implemented in institutions like the University of Oslo, digital storytelling therefore cannot be used as a tool for building individual identity and giving "ordinary" people "a voice", but as a tool for building institutional identity, it has been shown to work very well. It might have a potential for democratic identification with the institution, since it is implemented from below the hierarchy. Even though several of the original paradigmatical principles of the digital storytelling production process have needed to be changed, some of the most basic principles still remain. In institutional contexts, digital storytelling is shaped and reconfigured to fit the goals and ideologies of each of these contexts: "digital storytelling is at its most effective when embedded in a well-supported context that shapes the practice of self-mediated representation toward a shared purpose" (Burgess and Claebe 2009: 166). In order to fulfil the aim of the production (to celebrate the bicentennial of the University), the genre had to be adjusted in several important ways. Nevertheless, there is no doubt that the films produced should be categorised as digital stories. It is important to distinguish between a documentary or informational film, which might leave the narrator untouched and uncommitted towards the values and ideologies in play, and a first-person narrative which by its very construction includes the narrator in the unfolding of the plot. A classical digital story has the ambition of mediating between individual and community, and this is done through narration.

\section{Conclusion}

Even though the very idea of digital storytelling - capturing lives, creating community has always aimed towards constructing community as its goal (Lambert 2009b: 87-89), 
it has developed towards a more comprehensive institutional use over the last decade (McWilliams 2009). Digital storytelling programs are hosted mainly by educational institutions, community centres and cultural institutions. The implementation of digital storytelling at the University of Oslo should be seen as part of an ongoing change and increasing diffusion of the genre.

The CDS model of digital storytelling had from its very beginning a focus on the individual and the narrating self. Over the years digital storytelling has evolved to fit numerous different contexts. We observe an increasing diversity of digital storytelling practices as this genre expands to become an almost worldwide phenomenon (Hartley $\&$ McWilliam 2009). Today digital storytelling is often used in order to generate stories that promote collective identity and the interests of an institution or organisation. There has been a change in the digital storytelling genre from an individualistic towards a more collective perspective - a turn from narrating selves to narrating communities. Working with digital stories might strengthen the connection between the individual and surrounding communities and institutions. However, as this study has shown, the use of digital storytelling for the benefit of an institution might lead to profound changes in the main characteristics of the genre, or even give rise to conflicts with the film producers over the content and purpose of the narratives.

\section{References}

Burgess, J. \& Klaebe, H. (2009) 'Digital Storytelling as Participatory Public History in Australia', in Hartley, J. \& McWilliam, K. (eds.) Story Circle: Digital Storytelling around the World (pp. 155-166). Malden, MA: Willey-Blackwell.

Carpentier, N. (2009) 'Digital Storytelling in Belgium: Power and Participation', in Hartley, J. \& McWilliam, K. (Eds.) Story Circle: Digital Storytelling around the World (pp. 188-204). Malden, MA: WilleyBlackwell.

Center for Digital Storytelling (CDS) www.storycenter.org.

Guignon, C. (2004) Being Authentic. London: Routledge.

Hartley, J. \& McWilliam, K. (eds.). (2009) Story Circle: Digital Storytelling around the World. Malden, MA: Willey-Blackwell.

Hull, G. (2003) 'At Last, Youth Culture and Digital Media: New Literacies for New Times', Research in the Teaching of English, 38 (2), 229-233.

Hull, G. \& Katz, M.-L. (2006) 'Crafting an Agentive Self: Case Studies of Digital Storytelling', Research in the Teaching of English, 41 (1), 43-81.

Hull, G. \& Nelson, M.E. (2005) 'Locating the Semiotic Power of Multimodality', Written Communication, 22 (2005), 224-261.

Kaare, B.H. (2008) 'Youth as Producers: Digital Stories of Faith and Life', Nordicom Review, 29 (2), 189-201.

Kaare, B.H. \& Lundby, K. (2008a) 'Mediatized Lives: Autobiography and Assumed Authenticity in Digital Storytelling', in Lundby, K. (ed.) Digital Storytelling, Mediatized Stories: Self-representations in New Media (pp. 105-122). New York: Peter Lang.

\section{Acknowledgements}

Above all I want to thank the bachelor students who took part in MEVIT 3810 in 2010 and 2011 in the Department of Media and Communication at the University of Oslo. They produced 45 films and wrote 5 reports on their experiences and reflections about the genre. Much of what is presented here is based upon their work.

This study was part of a large international research project called "Mediatized Stories: Mediation Perspectives on Digital Storytelling among Youth", funded by the Research Council of Norway 2006-2010, led by Professor Knut Lundy, Dept. of Media and Communication, University of Oslo (http://www.intermedia.uio.no/mediatized/). 
Kaare, B.H. \& Lundby, K. (2008b) 'The "Power of Configuration” in Digital Storytelling', in Gächter, Y. et al. (eds.) Erzählen - Reflexionen im Zeitalter der Digitalisierung/Storytelling. [Reflections in the age of digitalization.] (pp. 99-110). Innsbruck: Innsbruck University Press.

Lambert, J. (2006, 2009a) Digital Storytelling: Capturing Lives, Creating Community. Berkeley: Digital Dine Press.

Lambert, J. (2009b) 'Where it all Started: The Center for Digital Storytelling in California', in Hartley, J. \& McWilliam, K. (eds.) Story Circle: Digital Storytelling around the World (pp. 79-90). Malden, MA: Willey-Blackwell.

Lindstad, M. (2006) Digital historiefortelling. [Digital storytelling.] Master's thesis, IMK, University of Oslo. http://www.duo.uio.no/sok/work.html?WORKID=47689

Lowenthal, P. (2009) 'Digital Storytelling in Education: An Emerging Institutional Technology?', in Hartley, J. \& McWilliam, K. (eds.) Story Circle: Digital Storytelling around the World (pp. 252-259). Malden, MA: Willey-Blackwell.

Lundby, K. (ed.) (2008) Digital Storytelling, Mediatized Stories: Self-representations in New Media. New York: Peter Lang.

Lundby, K. (2009) 'The Matrices of Digital Storytelling: Examples from Scandinavia', in Hartley, J. \& McWilliam, K. (eds.) Story Circle: Digital Storytelling around the World (pp. 176-187). Malden, MA: Willey-Blackwell.

McWilliam, K. (2009) 'The Global Diffusion of a Community Media Practice: Digital Storytelling Online', in Hartley, J. \& McWilliam, K. (eds.) Story Circle: Digital Storytelling around the World (pp. 37-75). Malden, MA: Willey-Blackwell.

Mead, G.H. (1934) Mind, Self and Society: From the Standpoint of a Social Behaviorist. Chicago: University of Chicago Press.

Meadows, D. (2003) 'Digital Storytelling: Research-based Practice in New Media', Visual Communication: Reflections on Practice, 2 (2), 189-193.

Meadows, D. \& Kidd, J. (2009) 'The BBC Digital Storytelling Project', in Hartley, J. \& McWilliam, K. (eds.). Story Circle: Digital Storytelling around the World (pp. 91-117). Malden, MA: Willey-Blackwell.

Tacchi, J. (2009) 'Finding a Voice: Participatory Development in Southeast Asia', in Hartley, J. \& McWilliam, K. (eds.) Story Circle: Digital Storytelling around the World (pp. 167-175). Malden, MA: WilleyBlackwell.

Thumim, N. (2006) Mediated Self-representations: "Ordinary People" in "Communities", in Herbrechter, S. and Higgins, M. (eds.) Returning (to) Communities: Theory, Culture and Political Practice of the Communal (pp. 255-274). New York: Rodopi.

Tolson, Andrew (2001) 'Being Yourself: The Pursuit of Authentic Celebrity', Discourse Studies Vol. 3 (4), 443-457.

Watkins, J. \& Russo, A. (2009) 'Beyond Individual Expression: Working with Cultural Institutions', in Hartley, J. \& McWilliam, K. (eds.) Story Circle: Digital Storytelling around the World (pp. 269-278). Malden, MA: Willey-Blackwell.

Birgit Hertzberg Kaare, Dr. philos, Professor, Department of Media and Communication, University of Oslo, b.h.kaare@media.uio.no 